\title{
CFD Analysis of Co-current Spray Dryer with Swirler at Air Inlet
}

\author{
Bharath G Wadone ${ }^{\# 1}$, Dr. G Manavendra ${ }^{* 2}$ \\ ${ }^{\# 1}$ PG Student: Dept. of Mechanical Engineering, \\ ${ }^{* 2}$ Associate Professor: Dept. of Mechanical Engineering, \\ Bapuji Institute of Engineering and Technology, Davangere, Karnataka, India \\ ${ }^{1}$ bharathwadone@gmail.com \\ ${ }^{2}$ manudvg1@gmail.com
}

\begin{abstract}
In this study, the analysis of the air flow, temperature and water vapour mass fraction patterns along with droplets behaviour have been carried out in a co-current spray dryer with swirler at air inlet, injecting the silica slurry using the pressure swirl nozzle, using the computational fluid dynamic (CFD) package (Ansys Fluent 16.0). The three dimensional geometry is developed using NX 10: Siemens PLM software. The gas phase is modeled using Euler's approach and the droplet phase using discrete phase model (Lagrange approach). The k- $\varepsilon$ model is used to model the effect of turbulence. Simulations showed the high velocity region lies between $0.5 \mathrm{~m}$ to $0.8 \mathrm{~m}$ in radial direction of drying chamber. Air temperature and water vapour mass fraction fluctuation is noted high in this high velocity region, confirms the drying rate is more in this region.
\end{abstract}

Keywords - Computational fluid dynamic (CFD), Spray dryer, Swirler, Viscosity

\section{INTRODUCTION}

Spray dryer is an essential unit operation for the manufacture of many products with specific powder properties, e.g. food, pharmaceuticals, chemicals etc. In spite of the wide uses of the spray dryers, they are still designed mainly on the basis of experience and pilot experiment [1]. One of the big problems faced by spray dryer designers and operators is the complexity of the spray/air mixing process in spray chamber [2] where the air flow patterns existing inside the spray dryer is considered as one of the primary factors that influence the residence time of droplet or particle, in turn the quality of the product produced by the dryer such as moisture content, size distribution, and bulk density. The detailed knowledge of spray drying process ensures good productivity, low energy consumption and high final product quality. The Spray dryer modeling has primarily dealt on its utility in various industries through empirical design because of practical difficulties due to large sizes, massive costs and complexity for measurement of process parameters like flow, temperature and water vapour mass fraction within the drying chamber.

Spray drying is an operation that transforms a solution or suspension into particles or powders by evaporation of the volatile. Spray drying usually is the end-point of a process and also influences the quality of the final product, more attention was paid to it over the last two decades. Therefore, CFD is the best tool to study the drying performance of chambers of different shapes, different arrangements of inlet drying gas, supplementary drying or cooling air inlets as well as effect of variation of parameters. Recent rapid developments in CFD and the ever-increasing computing power at decreasing cost makes it feasible to evaluate spray dryer designs without undertaking expensive experimental pilot or laboratory tests. Although simulation of the complex transport phenomena that occur in a spray dryer cannot yet be modeled with high accuracy, the results are nevertheless useful to guide design and operation of spray dryers when coupled with some empirical experience. Some commercial CFD codes are also available now to study the transport phenomena in spray dryers.

\section{Methodology}

\section{A. Geometry}

The pilot scale drying chamber geometry is used, as shown in Fig. 1. It is developed using NX 10: Siemens PLM software. The drying chamber is cylinder on cone type which is $4.435 \mathrm{~m}$ high at the highest point and 2.13 $\mathrm{m}$ wide at widest point. The air inlet has swirler (helical port) after the tangential entry. The geometrical dimensions of swirler is shown in Fig. 2. The pressure nozzle is located at the centre of drying chamber at a distance of $0.405 \mathrm{~m}$ from the highest point.

The hot air enters through the tangential entry at the top of the drying chamber and let into the drying chamber through swirler, induces the swirling of hot air. The swirling action leads to proper mixing of hot air and feed which helps in better evaporation, also lengthen the path of the feed droplets which improves its retention time in the drying chamber. 

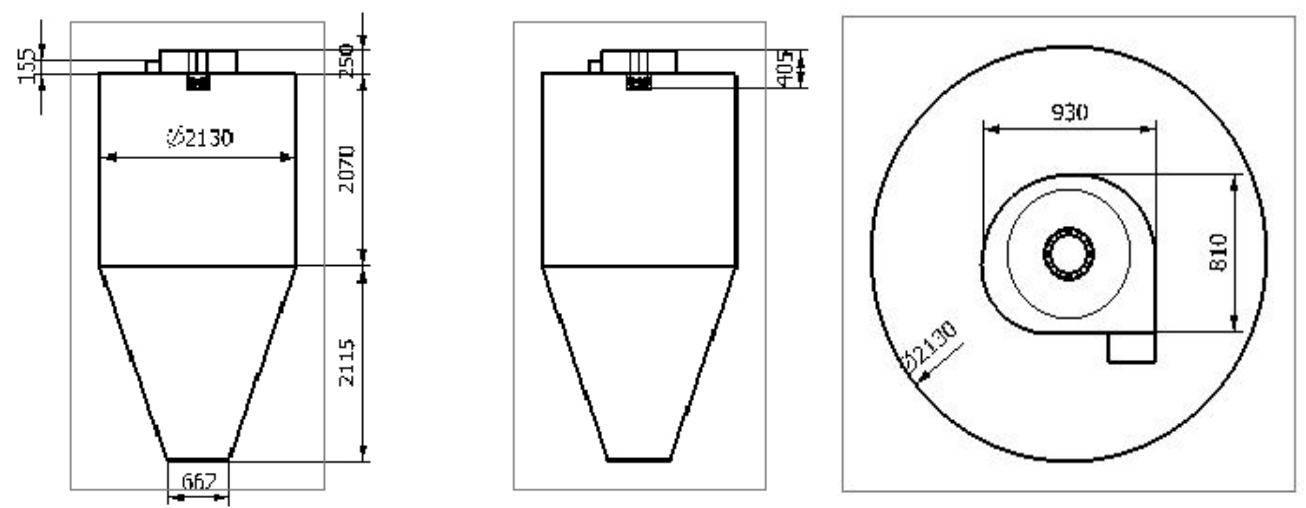

Fig. 1. The Spray Drying Chamber Geometric Dimensions
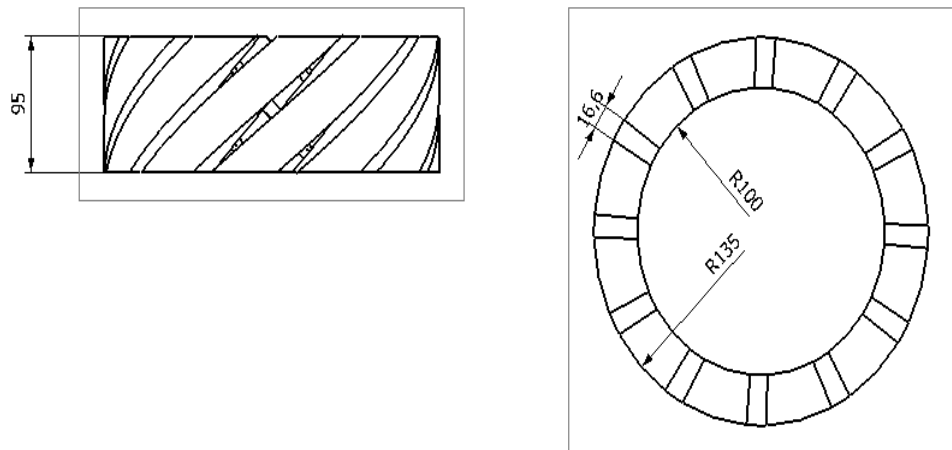

Fig. 2. The Swirler Geometric Dimensions

\section{B. Mesh}

The geometry is meshed using ICEM CFD 16.0, as shown in Fig. 3. A structured mesh is generated in the volume of the chamber using hexahedral elements. Due to the involvement of complexities in generating structured hexa mesh in swirler, the whole domain is divided into three parts and meshed for simplifying the mesh generation. The node density is increased at the wall to capture better boundary layer effects. In this simulation, more interest is in the flow away from the wall, hence very dense node is not used at the wall which would increase the computational efforts. The node density is increased near the swirler and drying chamber interface as large gradient exist.

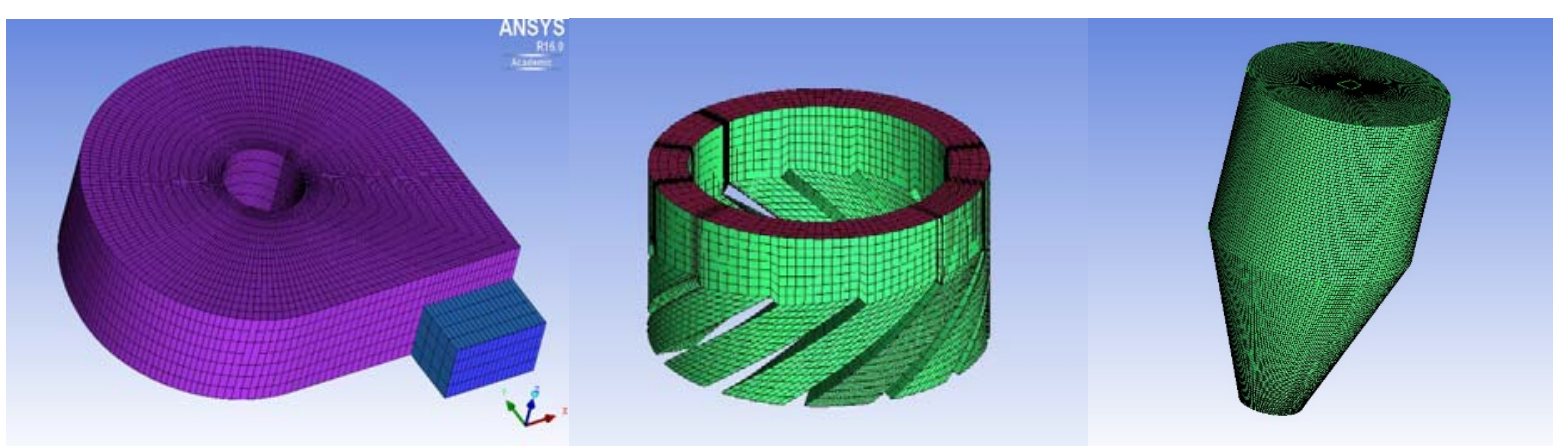

Fig. 3. Hexa Meshing of Spray Drying Chamber

Geometry with different number of mesh elements is studied in order to make solution grid independent. The number of elements in each mesh were $9.98 \times 10^{5}, 11.64 \times 10^{5}$ and $13.53 \times 10^{5}$ approximately. Comparison of average absolute velocity, temperature and water vapour mass fraction showed the results are independent of mesh. Thus the mesh with $9.98 \times 10^{5}$ elements is used in this study. Reducing the number of elements below the chosen mesh diminishes the quality of mesh. 


\section{Modeling}

This study involves multiphase flow. An Eulerian-Lagrangian model has been chosen as dispersed phase volume fraction is very less compared to continuous phase. A k- $\varepsilon$ model is used to model the turbulence. Because there is swirling flow in the drying chamber, the standard $\mathrm{k}-\varepsilon$ model is expected to be an appropriate choice for simulating such a flow and $\mathrm{k}-\varepsilon$ model convergence is considerably better than algebraic stress model and Reynolds stress model and it requires less computational efforts. The turbulent kinetic energy at the inlet is set at $0.027 \mathrm{~m}^{2} / \mathrm{s}^{2}$ and the energy dissipation rate at the inlet to be $0.37 \mathrm{~m}^{2} / \mathrm{s}^{3}$ which are the same values as those used by Kieviet [3].

In this study, the "escaped" boundary condition is used, where the droplets are lost from calculation at the point of impact with the wall [4]. The boundary condition used in this study are same as conditions of pilot scale spray dryer.

By experiment, viscosity of silica slurry with $9 \%$ concentration by weight is measured with respect to glycerol, whose viscosity is known. It is found, the viscosity of silica slurry is 85 centipoise at room temperature of $296 \mathrm{~K}$.

\section{Experimental Validation}

The spray dryer is modeled using the same geometrical dimensions of pilot-scale spray dryer. Simulation of spray dryer is conducted with the experimental input condition of pilot-scale spray dryer. The simulated outlet air temperature is found near to the experimental.

\section{III.RESULTS AND DISCUSSIONS}

Fig. 4 represents contour of air flow velocity at no spray conditions on middle plane in the spray dryer. Influence of feed droplets on airflow pattern is neglected due to its very small mass fraction. Air enters through tangential inlet with high velocity, flows through the swirler at higher velocity and reduces to lower velocity due to high expanding area of the drying chamber. Central core region has lower velocity $(0.5 \mathrm{~m} / \mathrm{s})$. Outer region has higher velocities compared to central core region is seen in Fig. 5. The outer fast flowing region shifts slightly outwards going down towards the outlet. The better drying of the droplets takes place in this region due to high convection by the fast flowing hot air. So, the region of high air velocity is preferable for drying. The fast flowing outer region is located between $0.5 \mathrm{~m}$ to $0.8 \mathrm{~m}$ radial distance.

Fig. 6 represents the velocity vectors at no spray condition, on middle plane in the spray dryer. Flow direction of air is shown in the drying chambers. It is noted, two zone of recirculation near the ceiling of drying chamber on both side of the nozzle. The zone of recirculation is undesired and unavoidable, it draws smaller size droplet into it and causes the droplet to stick to the ceiling of the drying chamber, it increases the residence time and also increases the temperature in turn degrades the quality of the particle.

Fig. 7 represents contour of air temperature at spray condition. It is seen, temperature decreases going down towards the outlet of the dryer. In axial direction, variation of temperature in central core region is minimum. Large variation in the temperature is seen in the fast flowing outer region.

Fig. 8 represents the air temperature profiles of air at different levels in the spray dryer. The variation of temperature in axial direction is minimum at central core region and the variation is maximum in the fast flowing region. The major variation in temperature is noted at $0.75 \mathrm{~m}$ radial distance. Largest temperature changes in radial direction is noted at $0.3 \mathrm{~m}$ level which is near to swirler, it is due to high difference in velocities between hot air and the droplets. It causes very high heat and mass transfer rates between them.

Fig. 9 represents the contour of water vapour mass fraction. Largest water vapour mass fraction variations is noted near the swirler due to large turbulence. Moving down towards outlet, in the central core region the water vapour mass fraction is less because droplet evaporation is minimum in this region. The outer fast flowing zone is observed as the region of high water vapour mass fraction as a result of more droplet evaporation.

Fig. 10 represents the mass fraction of water vapour profiles at different heights in the drying chamber. In the central core region, the variation of water vapour mass fraction is minimum. Variation of water vapour mass fraction is maximum in the fast flowing outer region $0.5 \mathrm{~m}$ to $0.8 \mathrm{~m}$ radial distance. This implies the drying takes place in this fast flowing outer region. 


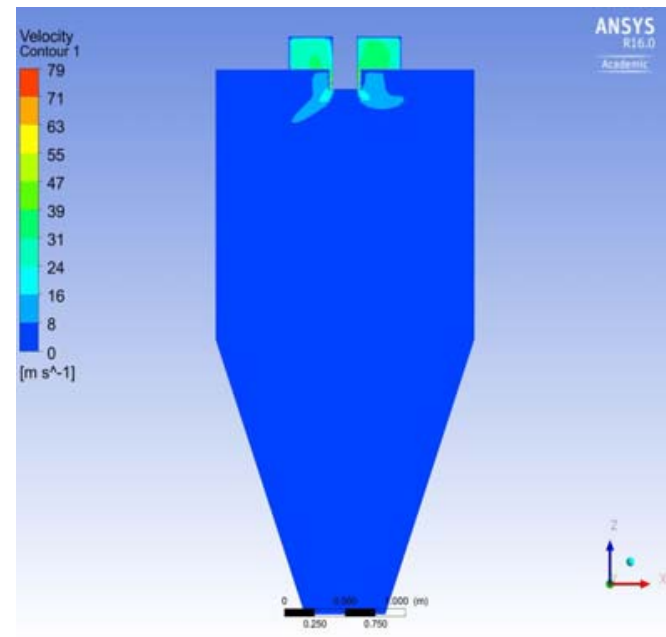

(a)

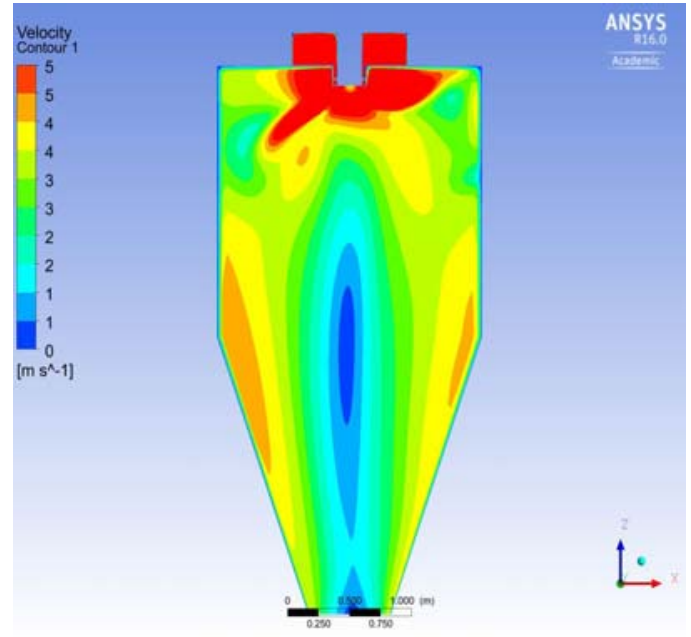

(b)

Fig. 4. Velocity contours at no spray conditions. (a) Global range (b) Narrow range

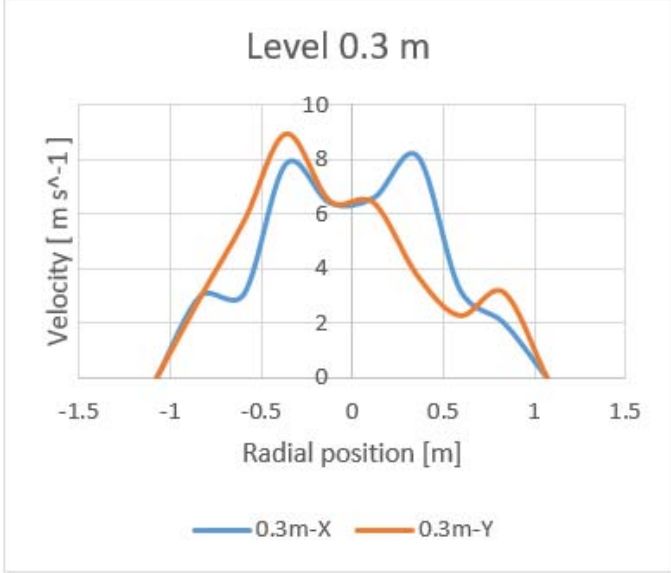

(a)

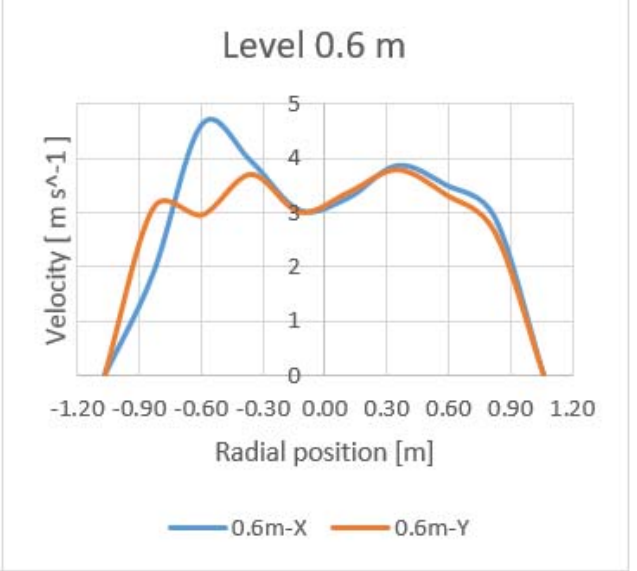

(b)

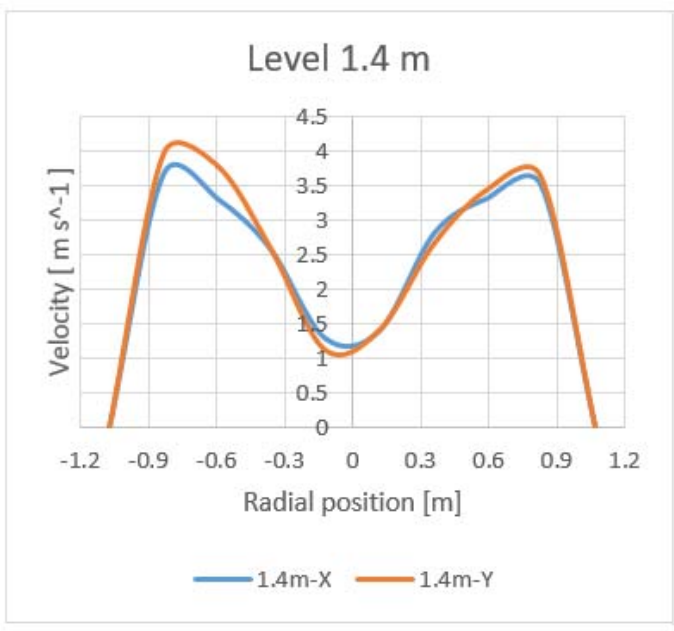

(c)
Level $2 \mathrm{~m}$

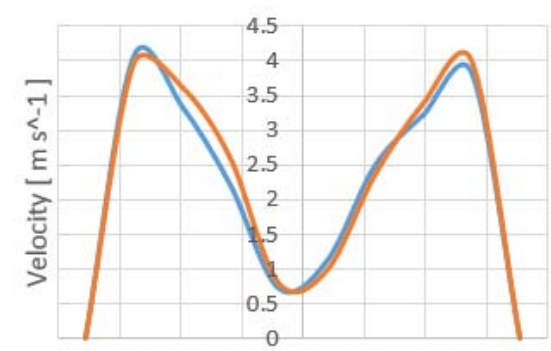

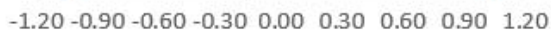
Radial position [m] 


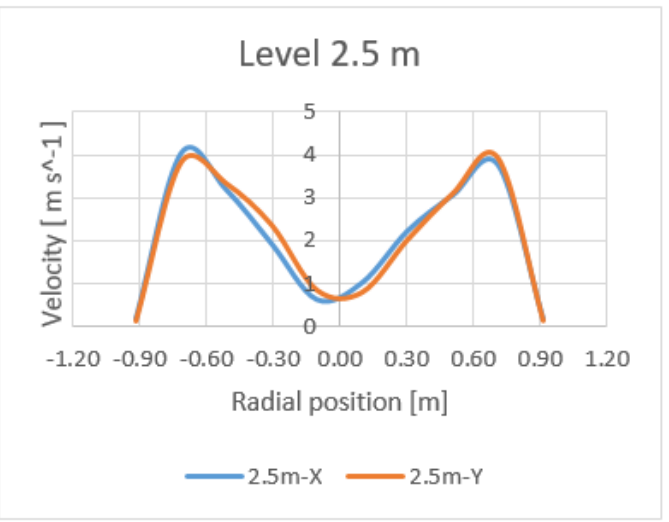

(d)

Fig. 5. Velocity variation in radial direction at different levels

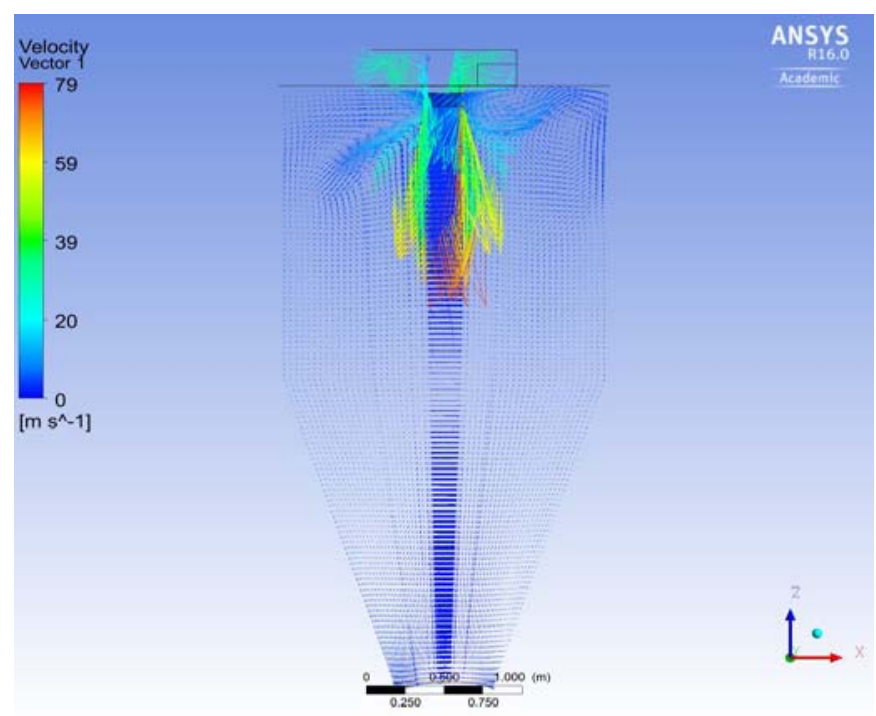

Fig. 6. Velocity vectors representing direction of flow in drying chamber.

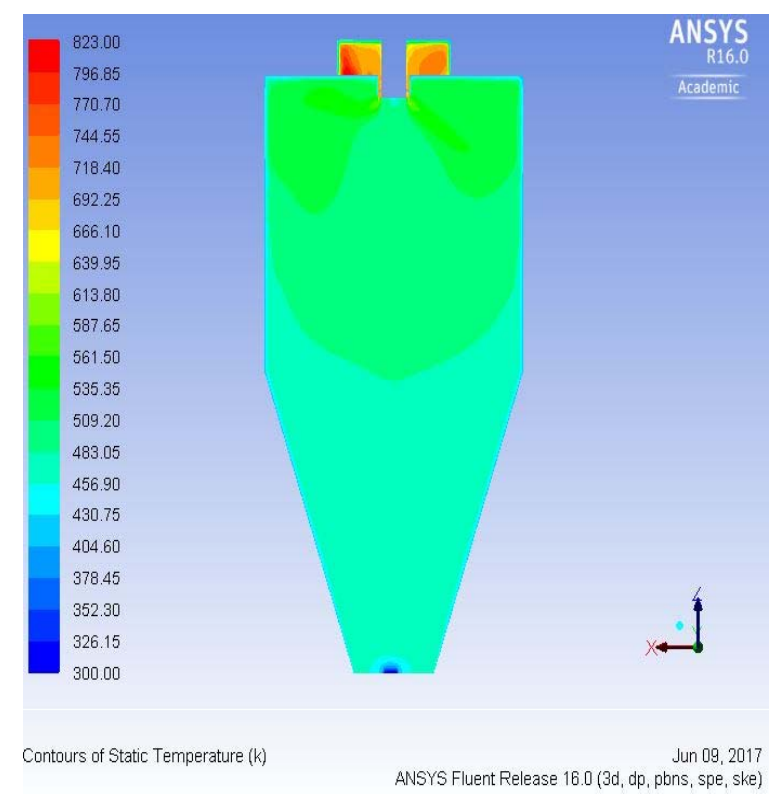

(a)

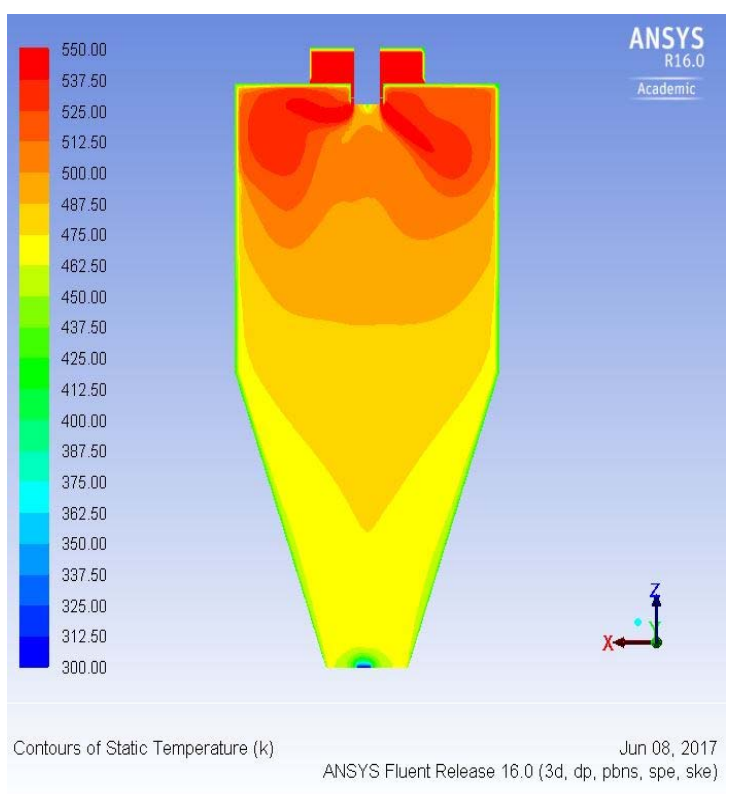

(b)

Fig. 7. Air temperature contours at spray conditions. (a) Global range (b) Narrow range 


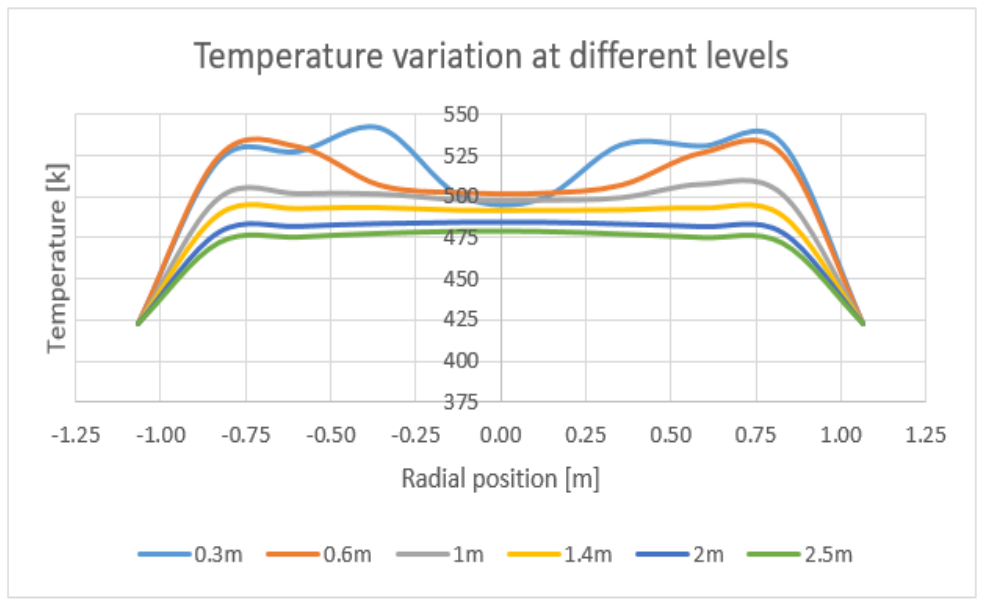

Fig. 8. Temperature variation in radial direction at different levels.

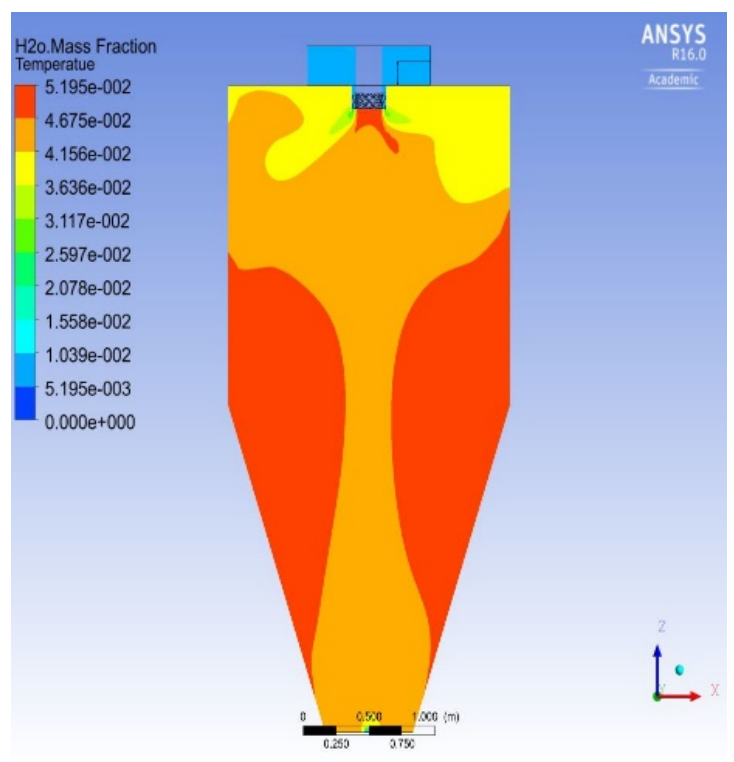

(a)

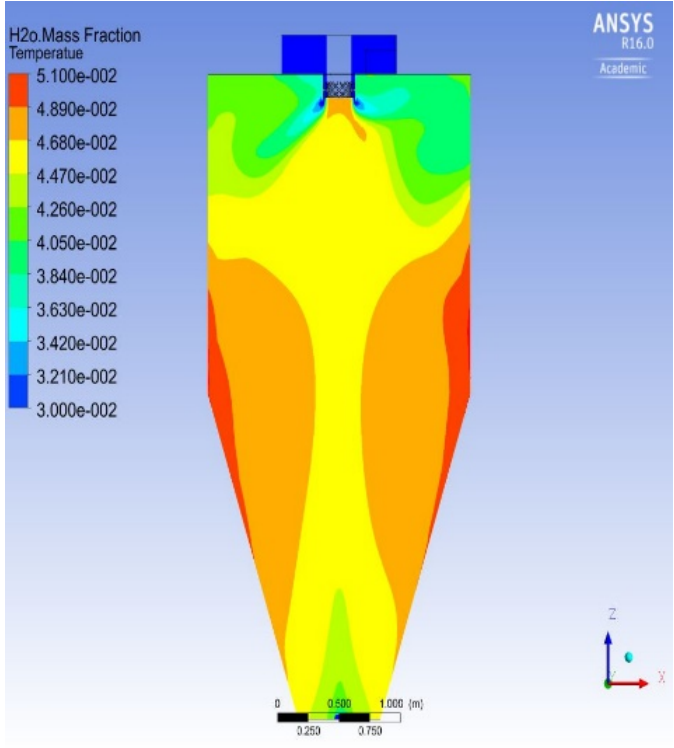

(b)

Fig. 9. Water vapour mass fraction in air contour at spray conditions. (a) Global range (b) Narrow range

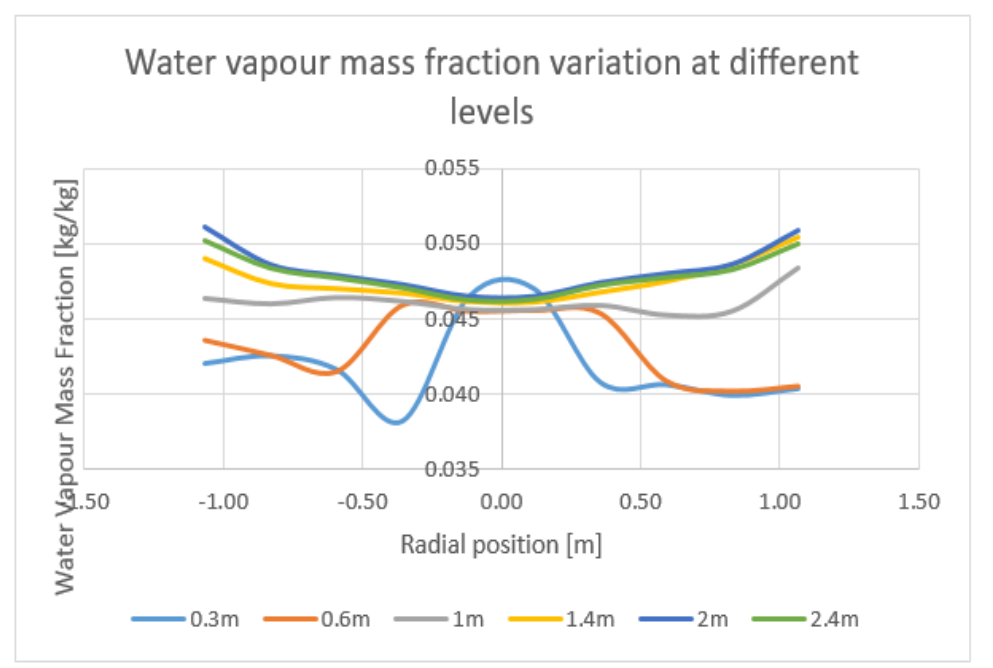

Fig. 10. Water vapour mass fraction variation in radial direction at different levels from ceiling. 
It is seen from the Fig. 11, the air flow pattern has high influence on the trajectories of the particles. Particles fate is mainly dependent on the air flow patterns. Air flow patterns is very important in the quality of the product, efficiency of the spray dryer. There is no much influence of droplets on the airflow pattern due to very small fraction of droplet compared to air.

For pressure atomizers, Rosin-Rammler diameter distribution model is used to describe the droplet size distribution. The maximum diameter of the droplet is 328 microns, minimum diameter is 1.5 micron. Fig. 12 shows the droplet diameter distribution in the drying chamber.

Fig. 13 represents the trajectories of the droplets coloured by droplet residence time. It is the time spent by the droplet inside the drying chamber. It is seen from the figure that most of the droplets are evaporated within $2.5 \mathrm{~m}$ distance from the ceiling of the drying chamber.

Fig. 14 represent the variation of evaporation time with droplet size. As anticipated, small droplets dry quickly compared to large droplets. Small droplets have the greater surface area/volume ratio, but larger droplets have lesser surface area /volume ratio. When the mixing of droplets and hot air is not perfect, smallest droplets dry quickly, hot air temperature comes down and thereby larger droplets come in contact with colder air during the longer part of drying time. Therefore, they have lower drying temperature in average than smaller droplets.

The droplet properties and heat and mass transfer characteristics of the tested case is tabulated in Table 1.

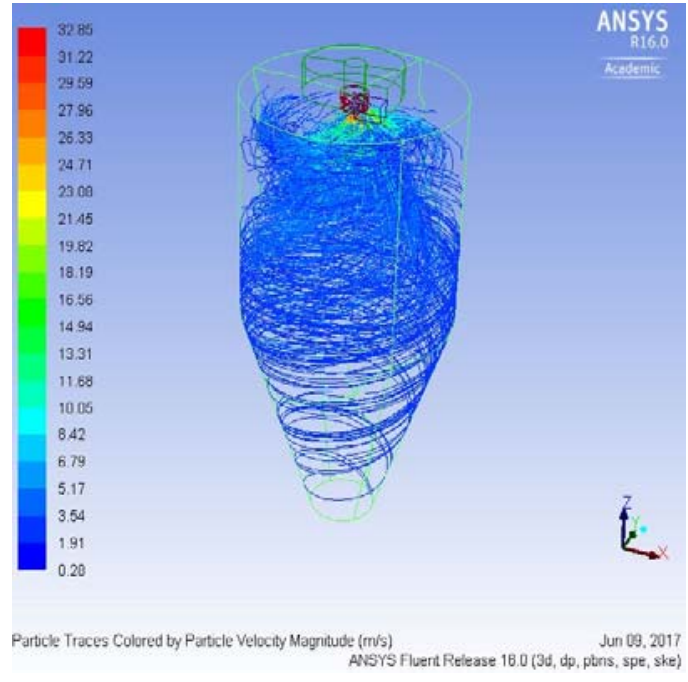

Fig. 11. Trajectories of droplets inside in drying chamber.

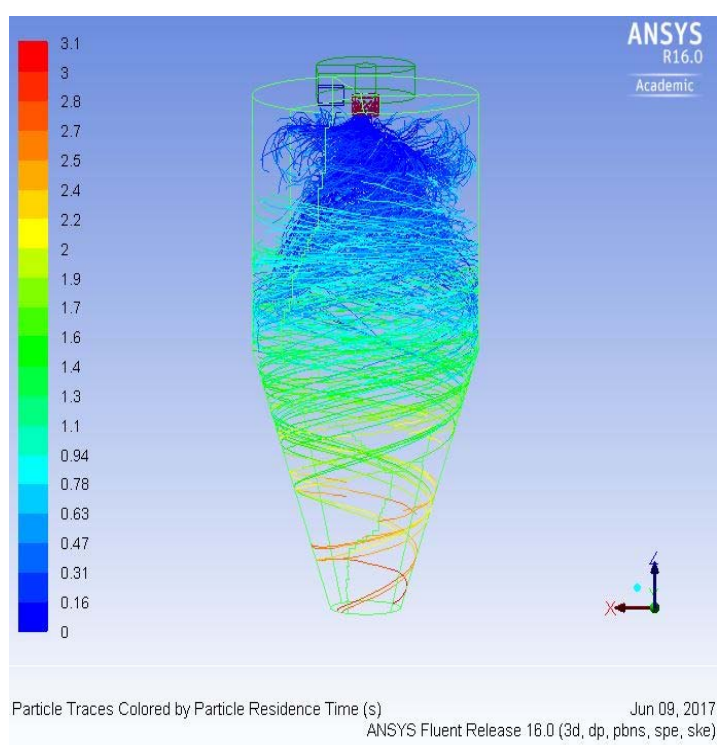

Fig. 13. Droplet trajectories coloured by droplet residence time (sec).

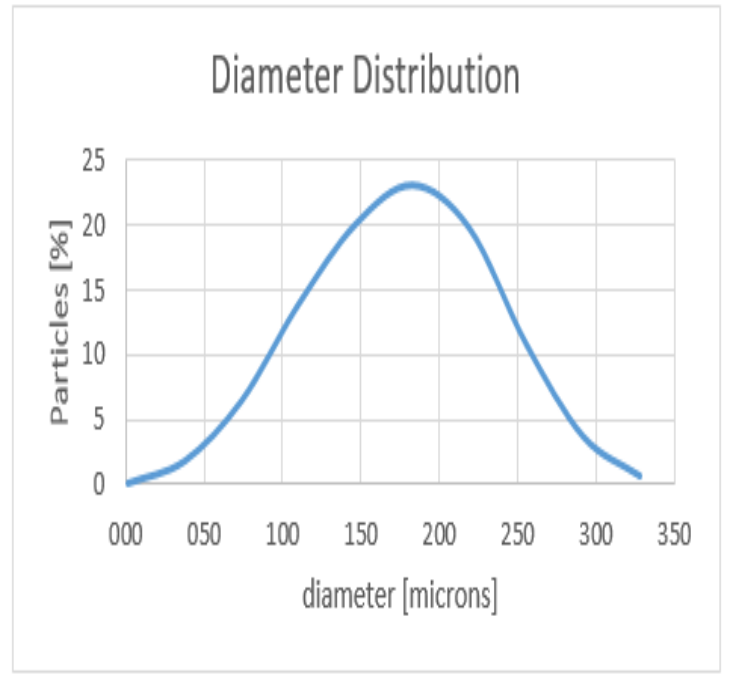

Fig. 12. Droplet Diameter distribution in drying chamber.

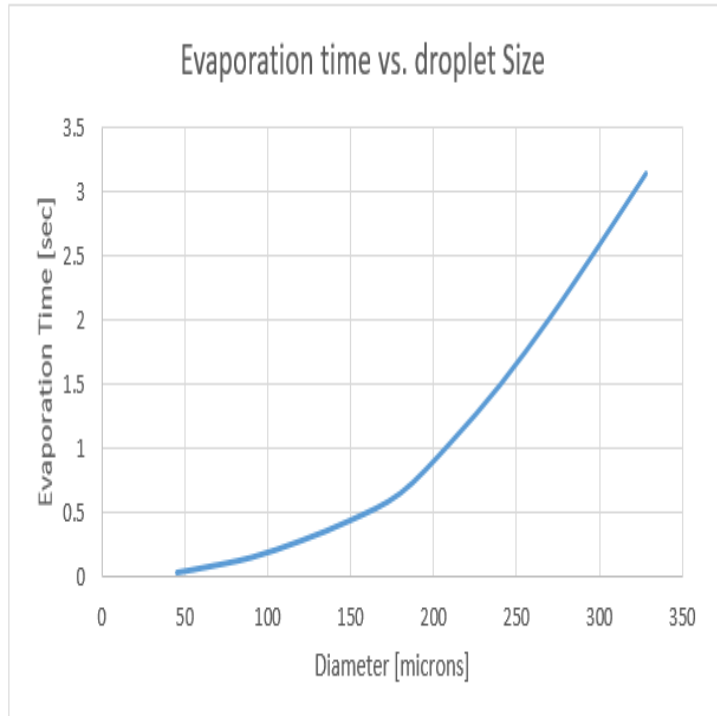

Fig. 14 Variation of evaporation time with droplet size. 
TABLE I

\begin{tabular}{|c|c|}
\hline Parameters & Case \\
\hline Minimum droplet size (microns) & 1.59 \\
\hline Maximum droplet size (microns) & 328.3 \\
\hline Mean droplet size (microns) & 173.42 \\
\hline Percentage of droplets hitting the wall (\%) & 33.6 \\
\hline Percentage of droplets escaped through outlet (\%) & 1 \\
\hline
\end{tabular}

\section{IV.CONCLUSION}

The main objective of spray drying technology is to produce the dried product of optimum quality. In order to improve the drying rate, it is important to study the air flow, temperature and water vapour mass fraction patterns and particle behaviour inside the drying chamber which will give better insight of the phenomenon occurring inside drying chamber. In this study, capability of CFD has been explored to model complex multiphase droplet drying.

It has been observed, high velocity region lies between $0.5 \mathrm{~m}$ and $0.8 \mathrm{~m}$ in radial direction of drying chamber. This region is the scope for high drying rate. In correlation to high velocity region, at different levels in axial direction, temperature of air decreases moving towards the outlet. It means more evaporation of droplet takes place in this region. The large variation in water vapour mass fraction is seen in the high velocity region, means more evaporation takes place in this region. Particle residence time, particle water mass fraction, particle temperature and particle diameter distribution is studied for better understanding of particle behaviour inside drying chamber.

\section{REFERENCES}

[1] Masters, K., Spray Drying Handbook, 4th ed., John Wiley and Sons, New York, 1985.

[2] Oakley, D., "Produce uniform particles by spray drying", Chem. Eng. Prog., October, pp. 48-54, 1997.

[3] Kieviet, F.G. Modelling Quality in Spray Drying. Ph.D. thesis, Endinhoven University of Technology, the Netherland, 1997.

[4] Huang Lixin, K. Kumar, Arun S. Mujumdar "Simulation of Spray Evaporation Using Pressure and Ultrasonic Atomizer - A Comparative Analysis", 2004.

[5] Fluent manual. Theory Guide, 2015.

[6] Saad Nahi Saleh. "CFD Simulations of a Co-Current Spray Dryer". World Academy of Science, Engineering and Technology, 2010.

[7] Arun S. Mujumdar, Li-Xin Huang, Xiao Dong Chen "An overview of the recent advances in spray-drying” Dairy Sci. Technol. 90 (2010) 211-224, 2010

[8] Anandharamakrishnan and Padma Ishwarya S. "Spray Drying Techniques for Food Ingredient Encapsulation” (C) 2015 John Wiley \& Sons, Ltd. Published 2015 by John Wiley \& Sons, Ltd.

[9] J.R. Gabites, J. Abrahamson, J.A. Winchester "Air flow patterns in an industrial milk powder spray dryer", chemical engineering research and design, 2010

[10] Angel Dharshini, Victor Paul, "Heat and Mass transfer Study in the Spray Drying of Tomato Juice”, Anna University, Chennai, 2008.

[11] F. G. Kieviet, J. Van Raaij, P. P. E. A. De Moor and P. J. A. M. Kerkhof "Measurement and Modelling of the Air Flow Pattern in A Pilot-Plant Spray Dryer", 1997. 